\title{
EL CONTRACTUALISMO \\ LIBERAL DE GAUTHIER \\ COMO FALSA IDEOLOGÍA ${ }^{1}$
}

\section{Las pretensiones del contractualismo liberal de Gauthier}

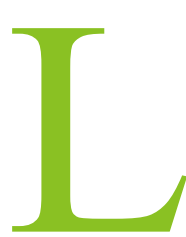

as teorías contractualistas contemporáneas han alcanzado un grado de refinamiento argumentativo tan elevado que cualquier lector que no sea un especialista en este área de la investigación filosófica, puede verse fácilmente intimidado por la enormidad de conocimientos que parecen necesitarse no sólo para comprenderlas, sino también para criticarlas de una forma interesante. Muchos conocimientos históricos, matemáticos, sociológicos, psicológicos y filosóficos se ponen en juego a la vez para formular estas teorías de tantísimas repercusiones morales, políticas y económicas. El contractualismo contemporáneo tiene realmente un efecto cauterizador sobre nuestra capacidad crítica cotidiana. En este aspecto se parece mucho a las teorías científicas y metafísicas más importantes y sofisticadas que tenemos. Tolle lege y después ya hablaremos, es la sugerencia que se nos hace.

Este estado de cosas esotérico unido a la facilidad con que puede encontrarse el contractualismo contemporáneo con la teoría matemática de la decisión racional y con determinadas ideologías sociales y teorías económicas, han sido circunstancias muy bien recibidas por el mundo académico profesional. El resultado final ha sido que una parte importante de la filosofía moral contemporánea se ha visto investida de pronto con una dignidad científica «prestada» que parecía impensable hasta la fecha, atenazada, como estaba, por intentos inconmensurables de dar cuenta de la vida y del vocabulario moral.

El carácter complejo y el aire de cientificidad que se adhieren, como una segunda naturaleza, a las teorías contractualistas han tenido, sin embargo, efectos positivos claros. Han propiciado, por un lado, que los «científicos morales» se organicen en una comunidad de intereses que funciona de una

\footnotetext{
${ }^{1}$ Este trabajo ha sido posible gracias a una beca posdoctoral de la Fundación Caja Madrid dentro del proyecto «El sujeto moral y político en las teorías contractualistas contemporáneas: John Rawls y David Gauthier».
} 
forma paradigmática y autónoma con relación al resto de las disciplinas filosóficas. También han promovido que aquellos que han logrado tener noticia de las teorías contractualistas más elaboradas y las han comprendido y las han aceptado total o parcialmente, descansen confiados ante la inmensa responsabilidad histórica y social que han asumido algunos de estos científicos morales. La responsabilidad adquirida es la de fundamentar la moralidad. Sin embargo, es posible que esta enorme responsabilidad, como ocurre muchas otras veces, descanse en un optimismo exagerado. El optimismo estribaría en considerar que existe «la» moralidad, que la moralidad tiene «una crisis de fundamentación» y que el contractualismo es «la única solución posible a esta crisis» (Gauthier, 1989, 19).

Ciertamente, si el contractualismo alcanzara su objetivo, entonces la humanidad podría descansar relativamente tranquila, aunque no, desde luego, los científicos morales. Nosotros podríamos vivir más o menos despreocupados, porque sabríamos que en nuestras sociedades hay grupos de personas especializadas que estarían en condiciones óptimas de justificar los juicios morales más básicos que todo individuo racional debería sostener. Sin embargo, los «científicos morales» tendrían ante sí una responsabilidad todavía mayor que la que habían asumido en un principio. Estas élites intelectuales tendrían que enfrentarse al siguiente problema. Dada la diafonía de las opiniones morales, y suponiendo que dos tesis morales acerca del mismo problema no pueden ser igualmente correctas -afirmación que aceptaría el contractualismo con su repulsa del emotivismo como teoría acerca del significado de los términos morales-, los teóricos contractualistas tendrían que arbitrar medios para decidir cuál de estas dos tesis está de acuerdo con sus principios morales, o de cualquier otro tipo, sobre los que descansaba la teoría menos afortunada, sean abandonados por sectores cada vez más amplios de la población. Desde luego, estas tareas posteriores no pertenecen al ámbito teórico estricto, sino que se acercan, a pasos agigantados, a las cuestiones propias de la ética aplicada y al peligroso terreno de las reformas educativas y sociales de gran alcance. Para ilustrar este punto, me gustaría poner dos ejemplos en los que se viera de qué forma un contractualista liberal como Gauthier tendría que intentar promover estas reformas.

Gauthier argumenta que existen cuatro criterios, basados en ciertos hechos difícilmente rebatibles, para determinar cuándo ciertas prácticas y formas de vida son superiores a otras. Siempre que una forma de vida permita a un mayor número de personas vivir en un mismo territorio, tener una esperanza de vida superior, un nivel de bienestar material más elevado y un horizonte mayor de oportunidades respecto de otra, entonces aquélla es superior a ésta (Gauthier, 1986, 288). Sobre la base de estos presupuestos, Gauthier sostiene que cuando los europeos introdujeron una tecnología superior 
a la ya existente en el territorio nativo norteamericano, estaban creando al mismo tiempo la posibilidad de que «muchas más personas vivieran una vida más larga y más abundante con oportunidades más amplias, aunque de alguna forma diferentes», a las ya existentes (Gauthier, 1986, 295). Por consiguiente, si a los indios se les hubiera dejado elegir entre abrazar las nuevas formas de vida de los nuevos habitantes o seguir con las suyas, entonces el hecho de que su territorio fuera ocupado no tendría por qué haber supuesto ninguna injusticia. Es más, Gauthier sostiene, de una forma aún más beligerante, que los habitantes nativos de Norteamérica «no tienen motivos de queja, por ser un acto irracional o injusto, contra el fracaso de los europeos a la hora de ganarse su consentimiento previo antes de establecerse en el nuevo mundo. Semejante consentimiento habría sido, sin duda, imposible de conseguir, dado que los indios no hubieran podido tener una comprensión previa de la nueva tecnología que amplió las oportunidades, pero suplantó sus viejas formas de vida» (Gauthier, 1986, 295-296). La apropiación de sus territorios estaba completamente justificada desde el momento en que esa tecnología podría hacer que las formas de vida europeas salieran ganando en todo si se las comparaba con las de los indios norteamericanos según los cuatro criterios antes mencionados.

A pesar de esta argumentación, hay muchas personas que todavía creen que aquella apropiación de territorio fue indebida desde un punto de vista moral y político. Una de las razones por las que sostienen esta creencia es la siguiente. Qué se considera un beneficio en una sociedad tecnológica de mercado y qué se considera un beneficio en una sociedad radicalmente distinta, es una cuestión insoluble desde el momento en que se apela en cada caso a criterios inconmensurables entre sí y que, por lo tanto, no se puede extrapolar unos cánones de una sociedad a otra. Para ciertas formas de vida, una mayor densidad de población no tiene por qué ser un valor, como tampoco tiene por qué tenerlo el llegar a ser el alcalde de un pueblo, si no se puede cazar como se cazaba antes. Contra este punto de vista, la única alternativa coherente para un contractualista liberal sería educar a estas personas para que no piensen ya más ese disparate. La publicación de un libro puede ser la primera piedra en ese proceso educativo.

Además de ésta, Gauthier hace otra incursión en el terreno de la ética normativa cuando, después de establecer que sólo se debe entrar en relaciones de cooperación con aquellos individuos o países de los que se puede esperar razonablemente un beneficio, afirma que «nosotros, los europeos occidentales y sus vástagos, cuyo pensamiento está modelado por la ideología contractualista, no tenemos motivos para esperar que sea rentable o beneficioso cooperar con los países superpoblados o subdesarrollados de la mayor parte del resto del mundo. Dada la finitud de los recursos de la Tierra, sus 
ganancias son nuestras pérdidas» (Gauthier, 1990b, 350). Realmente, esta conclusión, extraída de las premisas contractualistas liberales, es, como mínimo, provocadora, si no decididamente injusta, porque no tiene en cuenta la historia de colonización, sumisión, explotación y exterminio que ha caracterizado las relaciones de los países europeos con el resto del mundo subdesarrollado o, simplemente, no europeo.

A la luz de estos dos ejemplos, podemos concluir que una peculiaridad de la teoría de Gauthier consiste en transitar acríticamente desde un determinado modelo formal teórico hasta la justificación de situaciones sociales y políticas. El contractualismo liberal presupone un ahistoricismo contumaz.

Sea lo que sea de esta cuestión, con los dos ejemplos mencionados nos encontramos ante situaciones en las que las consecuencias de los postulados del contractualismo liberal de Gauthier no están en armonía o en «equilibrio reflexivo» con las creencias morales y políticas de sectores representativos de la población. Por lo tanto, o esta clase de contractualismo está equivocado, o las creencias morales de este grupo social lo están. Como Gauthier está completamente convencido de que el contractualismo representa la octava maravilla de las teorías morales, serán seguramente estos individuos quienes estén equivocados. En general, su actitud es siempre mantener que cuando nuestros juicios acerca de la justicia y la moralidad no están en consonancia con los resultados de su teoría contractualista, entonces debemos intentar reformar estos juicios, en lugar de repensar la teoría (Gauthier, 1993b,168).

Además de esta primera postura comprometida que acabo de esbozar según la cual los contractualistas, además de teóricos, deberían ser sobre todo reformadores sociales, cabe otra menos exigente políticamente. El contractualismo podría optar por mantenerse dentro del reducido terreno de la pura teoría. Si adoptara esta segunda actitud, entonces el contractualismo sería «el patrimonio esotérico de una élite» (Gutiérrez López, 1989, 199). La vida moral sería asunto de todos, pero la fundamentación de la vida moral sería el tesoro de determinadas minorías intelectuales en las que habría que confiar como los guardianes ignotos de la sabiduría moral. Esta posición es respetable, aunque se tenga que pagar el precio de dejar indefensa a la inmensa mayoría de la población frente a las amenazas de los compromisos morales que son incompatibles con el contractualismo.

Sin embargo, antes de plantear todos estos problemas prácticos, cabe preguntarse más fundamentalmente si las teorías contractualistas como la de Gauthier, en la que me centraré especialmente es este artículo, pueden cumplir con la elevada misión que se han encomendado de fundamentar la moralidad. La objeción principal que quiero hacer al contractualismo liberal de Gauthier es que descansa en presuposiciones morales y actitudes 
existenciales que no pueden ser asumidas por todos de una manera racional. Para mostrar esta tesis, me centraré sobre todo en la noción de «dotación natural» para hacer ver de qué modo Gauthier vuelca sobre ella una concepción del individuo dominada por una falsa ideología que lo convierte en un ser hecho a sí mismo, desnudo socialmente y que cree que puede utilizar su dotación natural como un instrumento de poder.

\section{2. ¿Cuáles son las condiciones reales de negociación?}

Se ha señalado repetidas veces que toda teoría contractualista debe incluir una caracterización completa y adecuada del «estado de naturaleza» o línea de salida (baseline), en la que se den indicaciones precisas acerca de cómo la teoría concibe a los individuos antes de comenzar el proceso negociador que les conducirá hasta el producto de la cooperación social y el sistema de concesiones y renuncias mutuas (Sugden, 1993a 5 y 10, Goodin, 1993, 123). Esta caracterización es, por tanto, una descripción de los individuos al margen de las transacciones sociales y de la formación de la sociedad concebida como un sistema de cooperación para el beneficio mutuo. El papel que juega la definición pre-social o, al menos, no-social del individuo, es dotar a cada uno de los participantes en la mesa negociadora con un punto de referencia que les sirva para hacer comparaciones entro lo que tienen y son antes de la negociación y lo que tendrán y serán después de finalizar las rondas negociadoras.

Además de esta cuestión inicial, también se ha señalado que el éxito completo de la empresa contractualista depende de que se consiga establecer una línea de salida que no incluya ningún presupuesto moral con el fin de que el resultado que se obtenga de las premisas de la teoría no esté contenido subrepticiamente en ellas y no se cometa, por tanto, una petición de principio (Goodin, 1993b, 116; Sugden, 1993b, 157). En este sentido, se ha distinguido entre un contractualismo débil y un contractualismo fuerte (Sugden, 1993b, 158). Para este último, sólo está permitido usar premisas que procedan de la teoría de la decisión racional con el fin de generar conclusiones morales. Como se presupone que la teoría de la decisión racional no contiene ninguna moralidad, el contractualismo fuerte procedería desde un «input» no moral hasta un «output» moral. En otras palabras, se trata de ver como surge la moralidad y su necesidad racional a partir de una situación en la que no hay componentes morales. Toda la fuerza del contractualismo liberal se basa en la posibilidad de dar este paso. Un contractualismo de este estilo está típicamente representado por la teoría moral de Gauthier. El contractualismo débil, por el contrario, se permite «inyectar» premisas que implican la tesis de la imparcialidad con el fin de establecer conclusiones morales igualmente imparciales. La teoría del velo de la ignorancia que 
usan Rawls (1971) y Harsanyi (1955) sería un ejemplo típico de esta segunda modalidad del contractualismo contemporáneo.

El contractualismo fuerte de Gauthier ha sido criticado, entre otras muchas cosas, porque no ha conseguido permanecer fiel al ideal teórico que se había propuesto. Por ejemplo, Goodin ha sostenido que «Gauthier termina pasando de contrabando ciertas asunciones morales en las premisas de su argumento moral» (Goodin, 1993, 117). En concreto, Goodin defiende que Gauthier no ha conseguido ofrecer un principio de justicia imparcial porque su modelo teórico da pie a tratar lo que es una auténtica necesidad y lo que es un deseo caprichoso como preferencias a las que habría que dar idéntico peso específico en una negociación racional en la que se estipule el grado de concesión relativo de cada parte (Goodin, 1993, 121-122). Gauthier no consigue formular un principio de justicia imparcial porque trata casos diferentes como si fueran semejantes.

Las consideraciones que haré en esta sección están relacionadas con esta clase de críticas que tratan de mostrar que Gauthier falla en su pretensión de no escabullir premisas morales en la base de su teoría. En concreto, mostraré de qué manera Gauthier es un representante refinado de un tipo de valores morales y políticos que él introduce en su teoría sin una justificación suficiente.

Gauthier sostiene que el punto de partida de la negociación en la que habrá que decir cómo repartir de una manera imparcial los frutos de la cooperación social, será justo cuando lo que cada individuo lleva a la mesa de negociación no se haya adquirido mediante coacción (Gauthier, 1986, 191-192). Esta salvaguarda (proviso) no es parte integrante del contrato social, sino que debe ser contemplada como una precondición para que los «hombres económicos» que se sientan a negociar puedan llegar efectivamente a un acuerdo que interese a todos por igual y que sea imparcial (Gauthier, 1986, 192). Ahora bien, aunque la salvaguarda será aceptada por individuos plenamente racionales -nadie aceptará racionalmente un punto de partida que incumpla esta condición-, hay que tener en cuenta que estos individuos tienen que iniciar la negociación a partir de una mercancía ya existente sin la cual sería imposible comenzar todo el proceso negociador. A esta mercancía la denomina Gauthier genéricamente «dotación natural» (natural endowment). La salvaguarda, por tanto, dice que esta dotación natural no debe ser el fruto de la coacción si los resultados de la negociación posterior han de ser justos y si se quiere reclamar para ellos la adhesión racional de todas las partes y no simplemente su adhesión por miedo a la coacción. Además, la salvaguarda, aplicada a la idea de dotación natural, introduce una estructura básica de derechos y deberes y un concepto de persona que está definido sobre la existencia de estos derechos y deberes (Gauthier, 1986, 210). 
Gauthier concibe esta dotación natural como el conjunto de todas aquellas capacidades físicas y mentales a las que cada uno tiene acceso directo y puede utilizar para conseguir ciertos productos derivados de su esfuerzo personal. La dotación natural junto con estos productos del trabajo individual constituyen «lo que cada uno aporta a la sociedad, al mercado y a la acción cooperativa» (Gauthier, 1986, 220). Esta aportación es diferente en diferentes personas y debería ayudar a determinar lo que cada cual puede pedir como parte legítima del fruto total de la cooperación social. Si la dotación natural y los bienes derivados de su uso no son fruto de la coacción, entonces los que están mejor dotados naturalmente y han usado esta dotación fructíferamente, deberían recibir más de la sociedad que los que están peor dotados o han sido más vagos o las dos cosas. Por lo tanto, dentro del sistema del contractualismo liberal de Gauthier, la desigualdad social no es nunca sinónima de parcialidad e injusticia, siempre y cuando los individuos presociales con distintas dotaciones naturales hayan respetado adecuadamente la salvaguarda (Gauthier, 1986, 217).

El problema principal que plantean estas condiciones surge cuando nos preguntamos hasta qué punto podemos decir que nuestras facultades físicas y mentales son realmente nuestras. En otras palabras, debemos preguntarnos por la verdad de la tesis que afirma que nuestra dotación cultural puede ser establecida correcta e inequívocamente de una forma totalmente independiente de cualquier contexto social, como exige la teoría de Gauthier. Lo que hay que preguntarse, pues, es hasta qué punto la dotación natural es completamente «natural», esto es, un producto en cuya constitución no ha intervenido ninguna estructura social.

Me parece claro que Gauthier siempre ha pensado, aunque sólo sea metodológicamente con el fin de construir su teoría contractualista fuerte, que la idea de dotación natural y la de individuo con derechos y deberes, en tanto que ésta queda definida por relación a aquélla, se contraponen a, y son independientes de, la idea de sociedad.

Nuestra conciencia cotidiana implica una concepción del individuo, con su dotación natural, como una entidad esencialmente aparte de la sociedad, por muy dependiente que pueda ser de la sociedad para su existencia y bienestar. (Gauthier, 1990a, 169. Véase también Gauthier, 1990b, 332).

Es decir, la dotación natural junto con los productos derivados de su uso directo -sobre todo en forma de propiedades o en forma de dinero en tanto que medida universal de toda propiedad- son lo que tenemos y somos antes de cualquier determinación de lo que llegaremos a tener y a ser en sociedad. Son, como se ha dicho ya, el punto de referencia sobre el que medir qué sería justo que recibiéramos si decidiéramos participar en la empresa cooperativa social. Son nuestra mercancía de negociación. 
Ahora bien, a esta tesis social y biológica radical, cabe contraponer otra no menos radical pero, según entiendo, más comprensible tanto desde un punto de vista metodológico para construir una teoría de la justicia social para «personas adultas» (Gauthier, 1988), como desde un punto de vista real. MacIntyre ha sostenido que para una concepción sustancial no dualista de la naturaleza humana «yo soy mi cuerpo y mi cuerpo es social, nacido de unos padres y en una comunidad que tiene una identidad social específica» (MacIntyre, 1981, 172). Al margen del contexto metafísico en el que MacIntyre hace esta afirmación, me parece que el mensaje es claro, un mensaje que, por lo demás, no han dejado de repetir numerosas teorías sociológicas de todo tipo y que apuntala nuestro conocimiento implícito de la influencia que tienen las relaciones sociales en la formación del yo. Mis capacidades físicas son en el fondo capacidades constituidas socialmente. Lo mismo sucede con mis capacidades mentales. De ser así, entonces es muy problemático sostener que hay unas capacidades físicas y mentales que pueden definirse presocialmente y que traemos a la mesa de negociación para determinar, al menos en parte, qué porción de la tarta social nos debería corresponder. Defender una línea de salida de este estilo es más que problemático, por no decir irreal.

Ciertamente, Gauthier es plenamente consciente de que caracterizar al individuo al margen del tejido de las instituciones sociales, es una de la tesis más problemáticas de la teoría moral que viene desarrollando desde hace tres décadas. En concreto, considera que su punto más débil es «la separación de la dotación natural del hombre de la estructura de la sociedad» (Gauthier, 1990a, 169). A la idea de individuo en tanto que ser cuyas características fundamentales son esencialmente presociales y a la idea de sociedad en tanto que resultado último de aplicar una concepción maximizadora de la racionalidad a las utilidades del sujeto, Gauthier contrapone un punto de vista radicalmente contrario a éste que quedaría descrito de la siguiente manera.

En lugar de pensar en las habilidades y talentos de un individuo como una dotación natural, podemos pensar en ellas como una creación eminentemente social. El individuo es entonces concebido no como un ser esencialmente al margen de la sociedad, sino más bien como el producto de la sociedad. La sociedad, por su parte, es concebida primariamente no como un instrumento para incrementar el bienestar de los individuos, sino como el marco dentro del cual los seres humanos, con sus características diferencias en las cualidades mentales, físicas y emocionales, son creados. (Gauthier, 1990a, 169).

A pesar de que Gauthier reconoce, tal y como era de esperar, la existencia de estas tesis opuestas a las suyas, sin embargo, ha seguido defendiendo esta ideología hobbesiana contra viento y marea. Necesariamente, entonces, 
habrá que preguntarse por las motivaciones de fondo que han guiado su elección radical.

Antes de intentar dar una respuesta a este interrogante, es importante dejar constancia de un problema que surge porque Gauthier no predica con el ejemplo. A mi modo de ver, existe una contradicción pragmática cuando se defiende que la dotación natural de los individuos que va a entrar en relaciones contractuales se define de una manera presocial y, sin embargo, resulta imposible encontrar un solo ejemplo en la obra de Gauthier en el que se vea claramente que existe esta dotación natural tal y como él la define. Todos los ejemplos de Gauthier contienen siempre personas maduras que están en posesión de numerosas habilidades físicas y mentales antes de entrar a negociar con los demás. Todas esas personas saben, por ejemplo, hablar, pescar, navegar, cultivar, negociar, etc. Ninguna de ellas es un pobre niño de Aveyron que, por carecer incluso de habla, sería incapaz de negociar nada. Incluso la capacidad lingüística, sin duda una de las más importantes para poder persuadir eficazmente y negociar con los demás, es ya una capacidad social o, al menos, una capacidad que no se puede desarrollar aislados de la sociedad ${ }^{2}$. Por lo tanto, si no hay habilidades físicas y mentales que no estén inafectadas por los contextos sociales en los que han nacido sus «poseedores», todas estas personas estarán ya altamente socializadas y habrán vivido alguna vez en un haz de relaciones sociales mínimamente complejo que, de una u otra manera, los habrá modelado y los habrá perjudicado o beneficiado. Todos los Robinson Crusoes y Evas que Gauthier esparce por las líneas de su libro más famoso, La moral por acuerdo, se encontrarían en este caso.

\section{Dotación natural y derecho de retribución}

Si mi crítica a la idea de «dotación natural» de Gauthier es correcta, el problema que surge ahora es saber si puede construirse esta noción de tal modo que nadie, sentado alrededor de la mesa de negociación, pueda sospechar que el otro tiene algo con lo que comerciar que ha adquirido por casualidad o por haber estado inserto en una trama de estructuras sociales complejas que le han beneficiado. De haber sido así, entonces estas posesiones no deberían quizás hacerse valer hasta el final como una mercancía que dota incondicionalmente a ciertos individuos de una capacidad de negociación superior a la de otros y que les permite pedir una ración superior

\footnotetext{
${ }^{2}$ Gauthier considera que el lenguaje no es un producto social, sino una condición para que exista la sociedad (Gauthier, 1990a, 332). Sin embargo, producto o condición de la sociedad, el lenguaje humano no es lenguaje sin la sociedad. Lo que el informe elaborado por Jean Itard sobre el niño salvaje de Aveyron mostraría, sería el efecto que tiene sobre el psiquismo humano y, desde luego, sobre el lenguaje, la carencia de una estructura social.
} 
del pastel del beneficio social cooperativo. Por ejemplo, quien considere que las supuestas dotaciones naturales son algo a medio camino entre lo que es nuestro pero que, sin embargo, no somos enteramente responsables de tenerlo porque nos ha sobrevivido en virtud de vivir incrustados en relaciones sociales de todo tipo -Ortega pensaba que nuestras capacidades físicas y psicológicas eran parte de nuestra circunstancia, es decir, algo con lo que nos encontramos sin haber sido enteramente sus artífices-, entonces mantendrá una actitud muy diferente y no presionará con tanto ahínco en la mesa de negociación como lo hacen los hombres económicos de Gauthier.

De acuerdo con esta reflexión, un problema que debería considerar toda teoría de la justicia social, para no operar con nociones demasiado simplistas que la obliguen después a perder verosimilitud cuando se la enfrenta al tribunal de la vida social, es el de ofrecer una teoría plausible del derecho que cada uno tiene a presionar a los demás y a exigir más que ellos como retribución a su contribución a la empresa social. Es, precisamente, esta pieza fundamental la que falta en la teoría de Gauthier y en otras teorías contractualistas contemporáneas. Es, sin embargo, la pieza que hace que su teoría pierda agarre entre individuos plenamente sociales como somos nosotros. La pregunta crucial es, por tanto, saber hasta qué punto podemos y debemos presionar en todo proceso negociador, incluso en un hipotético proceso negociador que nos conduzca hasta el establecimiento de los principios básicos de la justicia social.

Si intentáramos contestar esta pregunta en el contexto del contractualismo liberal, pienso que habría que decir que los hombres económicos de Gauthier siempre creen tener derecho a presionar al máximo en todas y cada una de las rondas negociadoras en las que intervienen dado que, aparentemente, viven como si no debieran nada a nadie antes de sentarse a negociar. Creen que con respetar la salvaguarda es suficiente para empezar a negociar sin cortapisas de ningún tipo. Pueden, por tanto, hacer valer su querida dotación natural hasta donde crean oportuno, pues están en su derecho. Recuérdese que la dotación natural servía para que cada individuo supiera hasta dónde podía pujar en la mesa de negociación siempre que respetara la salvaguarda.

A la luz de estas consideraciones, se puede extraer la conclusión de que los hombres económicos, sobre todo los que están o creen estar mejor dotados, se sirven de su dotación natural como si fuera un instrumento de poder. Tendré tanto más poder negociador y podré obtener tanto más del excedente de la cooperación social, cuanta mayor dotación natural tenga y cuanto más la explote para adquirir propiedades de todo tipo antes de empezar a negociar. Este es el fundamento de un sistema de reparto del excedente social cooperativo que Gauthier denomina «aristocracia natural» (1990a, 160). 
Relacionar el poder y la dotación natural no es novedoso. Como ha señalado Goodin, los mejor dotados y con mayores posesiones siempre estarán en condiciones más ventajosas para aguantar un proceso negociador largo que los que están peor dotados o tienen menos posesiones. Las concesiones a corto plazo les resultarán menos costosas a aquéllos que a éstos y, por lo tanto, llegarán más íntegros y con más poder negociador al final del proceso. Serán, en definitiva, negociadores más duros por regla general (Goodin, 1993, 119-120). Son, además, negociadores que pueden pedir más del producto de la cooperación social dure lo que dure la negociación. Debido a estas dos características, la doctrina de la aristocracia natural de Gauthier no dista mucho en su intención de fondo de la teoría que defiende Calicles en el diálogo Gorgias de Platón y que aquél recoge de Píndaro: lo justo es que el más apto tenga más que el inepto (488b).

Sin embargo, cuando las capacidades físicas y mentales de que goza cada cual se ven desde la perspectiva que las convierte en productos, al menos en parte, de las relaciones sociales, entonces no es posible utilizarlas de una forma tan simple, directa, despreocupada y prepotente como lo hacen los negociadores ideales de Gauthier. Ciertamente, sentados en la mesa de negociación, hay que respetar la salvaguarda que propone Gauthier. Pero respetar la salvaguarda es tan sólo una condición necesaria para que comience una negociación racional entre maximizadores de la utilidad. Además de esta condición hace falta, como mínimo, que cada cual aquilate de una forma justa hasta dónde puede y debe presionar a los demás teniendo en cuenta que su dotación natural no es hija de su exclusiva creación. Como he sostenido, Gauthier se mantiene mudo sobre esta cuestión.

A partir de este punto, sería interesante preguntarse cómo es que Gauthier no dice una sola palabra sobre este tema, sobre todo teniendo en cuenta que para muchas personas es un problema crucial en toda consideración acerca de la justicia social. Es, precisamente, la cuestión que subyace en las discusiones acaloradas que surgen cuando alguien defiende, como de hecho ocurre, que los ricos son ricos y merecen serlo porque son más inteligentes que los pobres. También es una cuestión interesante para todas aquellas personas educadas en la idea de que, por ejemplo, los niños más listos en la escuela debían ayudar a los niños que iban más retrasados, sin que jamás se les haya enseñado que sus talentos debían y podían ser explotados incondicionalmente para pedir más en una supuesta mesa de negociación o, simplemente, para pedir más en toda ocasión que se les presente en la vida.

Una contestación enteramente plausible al porqué de este silencio de Gauthier podría ser la siguiente. Dar por sentado que hay una dotación natural y continuar el razonamiento a partir de ahí es revelador de un determinado tipo de valores morales y de una determinada clase de sociedad. Lo 
que no es en ningún caso, es la simple descripción de un tipo de hecho fácilmente aceptable por todos o que todos tengamos que reconocer. No es ni siquiera aceptable desde un punto de vista metodológico para construir una teoría contractualista coherente. Con esta contestación entramos también de lleno en la discusión de que por qué Gauthier ha preferido siempre una concepción de las características esenciales del individuo que las convierte en esencialmente presociales, en lugar de una definición del individuo y de sus habilidades como entidades formadas en el seno de la sociedad.

\section{El contractualismo liberal como falsa ideología}

Gauthier no presenta las bases sobre las que descansa su contractualismo liberal fuerte como la expresión articulada de una opción moral particular que podría estar injustificada por diversos motivos, sino más bien como el sustrato más básico de «nuestra ideología».

La concepción de las relaciones sociales como contractuales subyace en el núcleo de nuestra ideología. (Gauthier, 1999b, 325)

Por «nuestra ideología» entiende el entramado común de ideas que los europeos occidentales y sus descendientes ideológicos en todas las partes del mundo sostienen de una forma prerreflexiva y que constituye la estructura profunda de su autocomprensión, es decir, de su autoconciencia (Gauthier, 1990b, 325-327).

Esta ideología, sin embargo, no es invariante ni espacial ni temporalmente. Cuando Gauthier sostiene que el contractualismo es nuestra ideología social, está afirmando que es una ideología que se puede detectar cada vez más claramente en Europa Occidental a partir del siglo XVII. Tampoco es una ideología completamente afianzada y omniabarcadora de todas nuestras conciencias, de modo que no deje resquicio a ninguna otra ideología. Más bien se trata de una tendencia consolidada en la historia de Occidente. Es el punto hacia el que se mueven cada vez más firmemente nuestras sociedades desde hace tres siglos (Gauthier, 1990b, 330).

Si ahora consideramos que Gauthier presenta su teoría de la moral por acuerdo como un intento refinado de reflejar fielmente esta concepción ideológica particular de las relaciones sociales, tendremos que concluir que la comprensión de su teoría es, en el fondo, un ejercicio de autocomprensión. Por este motivo, es fundamental preguntarse hasta qué punto debemos abrazar el contractualismo liberal más allá del mero ejercicio académico. Por lo que se refiere al problema particular del papel básico que juega la idea de dotación natural en el conjunto de la teoría de Gauthier, debemos preguntarnos si es cierto que esta idea forma parte de nuestra ideología. En 
caso de que contestemos que sí, debemos preguntarnos, en segundo lugar, hasta qué punto esa idea es parte de una falsa ideología.

Respecto a la primera pregunta, podría estar de acuerdo con Gauthier en su diagnóstico general según el cual tendemos cada vez más a explicar nuestro comportamiento social en términos contractualistas. No es demasiado difícil toparse con personas -sobre todo de determinadas clases sociales- que defienden la idea de la aristocracia natural no solamente sobre el papel, sino también para justificar su posición social privilegiada. Pero es que, además, defender sobre el papel la tesis de la aristocracia natural es síntoma de que uno se siente parte integrante de una clase social e intelectual privilegiada. Resulta difícil imaginarse a alguien que defendiera las tesis de Gauthier y que, sin embargo, considerara sinceramente que su dotación natural no vale apenas nada. Es muy probable que la mayoría de los que hemos leído el libro de Gauthier, independientemente de que aceptemos o no sus tesis, nos hayamos pensado como parte integrante de aquel grupo de individuos privilegiados que tendrían derecho a negociar fuerte debido a su maravillosa dotación natural. Sería raro encontrar entre nosotros a alguien que se viera muy preocupado porque considerara que su dotación natural vale muy poco y que, por consiguiente, va a conseguir una porción miserable del resultado de la cooperación social. No es de extrañar, pues, que el contractualismo liberal tenga tantos adictos en el mundo académico $\mathrm{y}$, sobre todo, en el mundo académico anglosajón. Es realmente difícil tener una forma de vida que te permita entender el libro de Gauthier y, más aún, aceptar sus tesis, si se es pobre y tonto a la vez. Es muy posible que nos guste el contractualismo porque nos gusta pensamos como pertenecientes a aquel grupo de privilegiados. Para eso, además, hemos inventado la teoría.

Según he dicho antes y a la luz de estas tendencias que acabo de apuntar, estaría de acuerdo con Gauthier en que nos deslizamos hacia formas de pensamiento social que están cada vez más en sintonía con los postulados del contractualismo liberal fuerte. Su teoría, en este sentido, bien podría ser una descripción adecuada de esta tendencia, que puede detectarse sobre todo en los individuos más privilegiados de la sociedad y en las sociedades más opulentas. Sin embargo, además del diagnóstico hay que considerar también si la sintomatología que describe no descansa sobre pilares de barro. Por consiguiente, hay que considerar ahora la segunda cuestión, la de si la ideología contractualista liberal es una falsa ideología.

Por lo que se refiere a esta segunda pregunta, Gauthier se limita a decir que «ideología» no quiere decir necesariamente «falsa conciencia» al estilo marxista. Ideología no es un concepto necesariamente peyorativo (Gauthier, 1990b, 325-326). También sostiene que detectar la existencia de una ideología contractualista asentada en el fondo de nuestra concepción de las relaciones 
sociales y humanas, no significa lo mismo que asumir su defensa incondicionada.

No estoy afirmando que la sociedad deba comprenderse o que podría entenderse, como si fuera contractual. Bien podría ser el caso que fuera absurdo entender la sociedad de esta manera. Lo que estoy haciendo es afirmar que nuestros pensamientos y acciones deben ser entendidos como si supusiéramos que todas las relaciones sociales tuvieran que ser racionalizadas en términos contractuales. (Gauthier, 1990b, 330)

Sin embargo, si la crítica que estoy haciendo al contractualismo de Gauthier es suficientemente sólida, entonces habría que afirmar que no debemos racionalizar todos nuestros pensamientos y acciones acerca de las relaciones sociales de una forma contractual. Y no es que no debamos hacerlo por una cuestión puramente sentimental, sino por atención a lo que parece que somos. Hago esta advertencia porque Gauthier catapulta toda crítica del contractualismo que él propugna al terreno de la sensiblería más indeseable.

Después de la reflexión, quizás podríamos desautorizar el contractual ismo. Podríamos insistir en que hay mucho más en las relaciones humanas que las convenciones que resultan del acuerdo. El contractualista puede admitir esto en tanto y cuando sostenga que estas otras características de las relaciones humanas no son esenciales y que son un residuo sentimental del pasado o una pátina emocional que proporciona un aura más placentera a lo que, de otra manera, es un mero artificio. (Gauthier, 1990b, 330-331)

Pero no toda crítica al contractualismo -como el propio Gauthier admitiría al considerar quiénes han sido y son sus críticos- está fundada en las emociones o en lo que no es esencialmente humano. Más bien, hay que preguntarse justamente lo contrario, es decir, hasta qué punto nuestra pretendida ideología contractualista liberal no está basada en supuestos no argumentados y en intuiciones que son el residuo sentimental de un tipo de persona y de valores que no son éticamente neutrales, de un tipo de persona a la que le gusta considerar que tiene lo que se merece y que se debe enteramente a sí misma. En otras palabras, debemos preguntarnos por el contractualismo como ideología en sentido peyorativo y como falsa conciencia, aunque estemos forzados a considerar que es una ideología muy extendida entre ciertos individuos y sectores sociales influyentes.

Es interesante constatar que Gauthier no se cuestione el contractualismo de esta manera negativa. Una explicación plausible de por qué no lo hace así sería que el contractualismo y la obra escrita y académica de los contractualistas no sería simplemente el intento de reflejar fielmente nuestra ideología, asentada definitivamente o todavía por consolidar, sino que el contractualismo académico y su radio de acción e influencia, por pequeño o grande que pueda ser, contribuye activamente a consolidar y a creer en las 
relaciones humanas como esencialmente contractuales. En este sentido, Gauthier sí defiende, indirectamente al menos, que las relaciones humanas son contractuales. Su obra es una aportación para asentar poco a poco estas ideas bajo el argumento de la autoridad académica.

Por tanto, según esta hipótesis, lo que delata el silencio sobre la cuestión del contractualismo como falsa conciencia, es que Gauthier, en el fondo, está defendiendo un tipo de ideas y de valores que no son en absoluto éticamente neutrales y que no constituyen simplemente una ideología, sino una ideología falsa. Las ideas de «hombre económico» y de «dotación natural» no son amorales. Por el contrario, están cargadas de connotaciones morales en tanto que con su uso se considera que, una vez aceptada la idea de dotación natural taly como la construye Gauthier, es éticamente legítimo presionar en la mesa de negociación hasta donde haga falta siempre que se cumpla la salvaguarda, sin tener en cuenta para nada el problema de nuestro derecho a presionar de esta manera tan feroz.

Contra esta actitud, he sostenido que, como mínimo, hay que mantener una postura cautelosa que nos impida vernos a nosotros mismos como creadores exclusivos de nuestras cualidades y posesiones físicas y mentales, aunque eso no quiera decir que no debamos sentirnos en parte responsables de lo que tenemos y somos. He sostenido también que quien defienda esta tesis plausible y, según mi punto de vista, más realista que la de Gauthier, no puede ver en los cimientos de la teoría contractualista liberal una posición éticamente neutral. Pero es que todavía menos neutrales éticamente pueden verlos ciertas religiones y teorías morales que han constituido, y siguen constituyendo, el núcleo compartido y, según MacIntyre, caótico y deshilvanado, de nuestra ideología moral (MacIntyre, 1981). Hay religiones y teorías morales para las que nuestra valoración auto-glorificante de muchas de las pertenencias psicológicas y materiales que consideramos como nuestro tesoro más preciado y ganado a pulso es sólo la manifestación de una única actitud moral: la vanidad. Además, considerar la defensa de una supuesta dotación natural como una actitud vanidosa, es racional para estas religiones y teorías éticas, desde el momento en que aceptan que es imposible delimitar claramente, en elámbito de nuestras habilidades físicas y mentales, entre lo que es puramente natural y lo que está construido socialmente. Ante la duda, lo éticamente valioso es aceptar que lo que tenemos no nos corresponde realmente.

Ante el dilema que nos plantea la necesidad de decidir entre estas tres posturas rivales -la dotación natural como propiedad asocial a nuestra exclusiva disposición, como circunstancia o como vanidad-, sólo cabe decir aquí que deberíamos pensar en su solución de una manera que no sea ni caprichosa ni esté subordinada a la defensa de ciertos intereses y valores morales 
que fueran previos a la elección. Lo que he tratado de mostrar en estas páginas es que la doctrina de la aristocracia natural sobre la que se asienta la teoría contractualista de Gauthier debería ser un candidato eliminado de este dilema. En resumen, la defensa indirecta del contractualismo sosteniendo que se trata de una descripción abierta de nuestra ideología prerreflexiva, no sirve como razón suficiente para mantener la alternativa de Gauthier entre las opciones posibles. Su teoría es el reflejo de una falsa ideología. Y lo es porque aceptar su idea de hombre económico y de dotación natural como un dato absoluto es, de hecho, introducir una premisa moral en el inicio de su argumentación contractualista. Que es una premisa moral se destaca en cuanto se compare la valoración y uso que hace el hombre económico de la dotación natural con la valoración que se puede hacer de esta noción desde otros puntos de vista. Gauthier, por tanto, sí que introduce premisas morales en su argumentación contractualista. Gauthier delimita ciertos valores morales y los pone directamente en el centro de su teoría contractualista como si no estuvieran allí presentes. Para que no se note la presencia de estos valores morales nos dice que lo que hay en su lugar es el reflejo neutral de nuestra autoconciencia social, sin tener en cuenta que al intentar reflejar nuestra ideología contractualista se está contribuyendo a creer falsamente en ella.

\section{Rawls y Gauthier: dotación natural y moralidad}

En esta última sección quiero defender la tesis de que Gauthier no llega directamente a su caracterización de la dotación natural atendiendo a los datos más relevantes de que disponemos para hablar sobre su existencia, sino indirectamente a través de la discusión con John Rawls.

Como es sabido, la noción de «dotación natural» es clave para entender los debates internos dentro de la tradición contractualista contemporánea. Gauthier, como miembro destacado de esta tradición, no está en condiciones de cuestionar esta idea desde su raíz, como he intentado hacer aquí, sino que se limita a expurgarla de todos los problemas que se le han ido adhiriendo con el fin de hacerla más utilizable teóricamente. El que Gauthier haya aceptado los términos de la polémica dentro del contractualismo es, entre otras, unas de las razones por las que su teoría introduce supuestos no argumentados e indefendibles convirtiéndola así en un objeto más vulnerable a las críticas de lo que sería deseable.

Gauthier acepta acríticamente de Rawls la tesis de que existe una dotación natural. Sobre este terreno común, Gauthier discute con Rawls de qué forma debemos considerar la dotación natural en el estado de naturaleza previo al acuerdo moral y al establecimiento de los principios de la justicia social. Es aquí donde un autor y otro difieren profundamente. Sin embargo, 
si mi crítica es adecuada, la discusión entre ellos y sus seguidores está mal enfocada desde su inicio. No hay que preguntarse por el papel y la valoración que merece la dotación natural en el conjunto de la teoría contractualista. Lo que hay que cuestionarse es la idea misma de dotación natural. Desde el momento en que tanto Rawls como Gauthier están ciegos para ver este problema, podemos concluir que ambos albergan presupuestos que descansan en una falsa concepción del sujeto social y moral. Lo que salga de una teoría que acepta la existencia de una dotación natural no puede ser otra cosa que un resultado altamente dudoso.

La controversia entre Rawls y Gauthier a propósito del rendimiento que extrae uno y otro del concepto de dotación natural es suficientemente conocida y aquí sólo la recordaré en sus líneas generales.

Rawls parte del supuesto de que la distribución de las habilidades que constituyen nuestra dotación natural no es algo que merezcamos (Rawls, 1971, 104). Éste es el motivo principal por el que hay que situar a los individuos detrás del velo de la ignorancia antes de que decidan cuáles son los mejores principios de justicia que deben regir las instituciones básicas de la sociedad. Para que esta decisión sea imparcial y justa, los sujetos deben desconocer cuál será su situación en la sociedad real por lo que se refiere a su posición social y económica, habilidades físicas y mentales, intereses concretos o planes de vida. El velo de la ignorancia asegura la imparcialidad del proceso de deliberación y de su resultado. Pero es que, además, puesto que no podemos reclamar un derecho exclusivo sobre nuestra dotación natural, dado que ésta está sujeta a contingencias de todo tipo que no deben determinar, desde un punto de vista moral, cómo hay que repartir el producto de la cooperación social, los individuos que deliberan sobre los principios de la justicia social considerarán los dones naturales de los miembros de la sociedad como un patrimonio común y los beneficios colectivos que procedan de la explotación de estos dones como susceptibles de ser distribuidos de acuerdo con el principio de la diferencia (Rawls, 1971, 101-102). En el fondo, pues, el velo de la ignorancia tiene la función de mitigar al máximo los efectos de una hipotética lotería natural a la hora de elegir justa y racionalmente los principios de la justicia social. Ésta es la justicia como equidad.

Gauthier, sin embargo, considera que el velo de la ignorancia de Rawls es demasiado grueso e impide que la teoría contractualista tome en serio la noción de individualidad. El peligro de la teoría de Rawls es que si se hace desaparecer toda diferencia individual en el punto de partida de la negociación, entonces, debido a las condiciones de extrema incertidumbre bajo las que son elegidos los principios de la justicia, las personas reales no podrán identificarse retrospectivamente con el pacto al que se ha llegado (Gauthier, 1993a, 156). El temor de Gauthier es, por tanto, que la teoría de 
Rawls carezca de toda plausibilidad social real y, ala larga, de todo interés tanto para los especialistas como para los que no lo son. Dicho de otra forma, el argumento contractualista resultará verosímil desde el punto de vista particular de cada miembro de la sociedad si y sólo si cada uno puede comprobar que, dada su situación, no hay mejores principios de la justicia, aceptables por todos, que los que han sido elegidos. Gauthier niega que Rawls pueda ofrecer esta garantía, sobre todo a los individuos que han sido muy favorecidos por la lotería natural. Estos individuos considerarán, tras el pacto, que se encuentran en una posición de contribuyentes cuasi netos a la empresa social con relación a otros miembros de la sociedad. Como consecuencia, estos individuos podrían recusar el pacto alcanzado sobre la base del velo de la ignorancia de Rawls. En tanto que individuos racionales maximizadores, rechazarán el pacto por no ser racional.

Para que esta recusación no tenga lugar, Gauthier considera que hay que sostener firmemente la existencia de una dotación natural distintiva que puede establecerse al margen de cualquier proceso social de constitución, porque sólo así cada individuo puede calcular qué parte de los bienes que actualmente disfruta es un verdadero beneficio cooperativo, y qué parte corresponde a lo que de todas formas habría tenido en caso de no haberse llegado a un acuerdo. Los principios de la justicia social se deben aplicar sobre el excedente que resulta de la cooperación social y no sobre los bienes que uno habría disfrutado de todas las maneras aunque no hubiera habido cooperación social. Si de esta manera se firma un contrato social, entonces los individuos que han sido muy beneficiados, por la lotería natural podrán estar seguros de que la cooperación social no les convierte en contribuyentes natos. Son éstos los motivos internos que llevaron a Gauthier a defender cierta versión de la idea de «dotación natural» y a darle un nuevo juego dentro de la tradición contractualista.

Sin embargo, reivindicar el derecho de utilizar la dotación natural como base para establecer los principios del reparto justo del excedente social cooperativo resta también plausibilidad social real y, a la larga, interés, a la teoría de Gauthier, porque es muy difícil identificarse con sus individuos negociadores si no se defiende a pies juntillas y antes de toda argumentación un tipo de valores morales como los de Calicles. Una vez más, el problema verdadero es el de ponderar de una forma justa, si es que puede hacerse, hasta dónde se debe presionar a los demás teniendo en cuenta que las dotaciones naturales no son creaciones originales nuestras. Éste era un problema que, sin embargo, Gauthier dejó totalmente al margen porque lo que primariamente le interesaba era criticar a Rawls y superar las posibles deficiencias de su teoría. Pero esta crítica le llevó a un terreno difícilmente defendible 
cuando no se aceptan las premisas que aporta la tradición contractualista contemporánea.

Dentro de esta inercia de disputa interna en el seno del contractualismo, es también comprensible que Gauthier no haya sopesado tampoco la posibilidad de que todo lo que suena a una reclamación, sea parcial o exclusiva, de las habilidades mentales y físicas de que disfrutamos y de los beneficios que su uso no coactivo nos reporta, sea visto como expresión de la vanidad. Desde este punto de vista más radical, más allá del hecho de que el hombre económico sea el hombre auto-interesado, el hombre económico es el hombre vanidoso y bien pagado de sí mismo. Si no me dan lo que yo pido en la mesa de negociación de una manera que yo considere justa según el principio de la concesión relativa minimax, me retiro de ella porque siempre tengo mi dotación natural y esa dotación no se la debo a nadie.

Bien sean las teorías que consideran que no cabe una definición presocial del individuo, o el Eclesiastés, para el que todo es vanidad, quienes tengan razón, lo que es seguro es que la teoría de Gauthier sólo puede funcionar como descripción refinada de una falsa conciencia social.

\section{BIBLIOGRAFÍA}

Gauthier, David (1986). Morals by Agreement. Oxford: Clarendon Press. Versión española La moral por acuerdo. Barcelona: Gedisa, 1994 (trad. Alcira Bixio).

- (1988), «Moral artifice». Canadian Journal of Philosophy, Vol. 18, pp. 385-418.

- (1989). «¿Por qué contractualismo?»Doxa, 6: 19-38. (Trad. Silvia Mendlewiez y A. Calsamiglia).

- (1990a). «Justice and Natural Endowment: Towards a Critique of Rawls's Ideological Framework». En Moral Dealing. Contract, Ethics and Reason. Gauthier, David. Ithaca: Cornell University Press: 150-170.

- (1990b). «The Social Contract as Ideology». En Moral Dealing. Contract, Ethics and Reason. Gauthier, David. Ithaca: Cornell University Press: 325-354.

Goodin, Robert E. (1993). «Equal rationality and initial endowments». En Rationality, Justice and the Social Contract. Themes from Morals by Agreement. Sudgen, Robert y David Gauthier (eds.). Ann Arbor: The University of Michigan Press: 116-130.

Gutiérrez López, Gilberto (1989). «Racionalidad consecuencialista y restricciones deontológicas». En El fundamento de los derechos humanos. Gregorio Peces-Barba Martínez (Ed.) Madrid: Debate, pp. 195-201.

Harsanyi, J. C. (1955). «Cardinal welfare, individualistic ethics and interpersonal comparison of utility». Journal of Political Economy, vol. 63: 309-321.

MacIntyre, Alasdair (1981). After Virtue. A Study in Moral Theory. Notre Dame: University of Notre Dame Press. 
Rawls, John (197 1). A Theory of Justice. Cambridge, Mass.: The Belknap Press of Harvard University Press.

Sugden, Robert (1993a). «The Contractarian enterprise». En Rationality, Justice and the Social Contract. Themes from Morals by Agreement. Sugden, Robert y David Gauthier (eds.). Ann Arbor: The University of Michigan Press: 1-23.

-(1993b). «Rationality and impartiality: Is the contractarian enterprise possible?». En Rationality, Justice and the Social Contract. Themes from Morals by Agreement. Sugden, Robert y David Gauthier (cds.). Ann Arbor: The University of Michigan Press: 157-175. 